\title{
Studies on Conditioned Responses in Fishes. Part II.
}

\author{
By \\ H. O. Bull, B.Sc., \\ Biologist at the Dove Marine Laboratory, Cullercoats, Northumberland.
}

With 11 Figures in the Text.

\section{CONTENTS.}

I. Introduction

II. The capacity of the wrasse, Crenilabrus melops (L.), to differentiate between two different sounds. Being a continuation of the experiment described in Part I, p. 508

III (a) The capacity of the plaice, Pleuronectes platessa (L.), to form a conditioned response towards visual stimuli. . . . . . . .

(b) The capacity of the coal-fish or saith, Gadus virens (L.), to form a conditioned response towards visual stimuli . . . . . .

(c) The capacity of the cod, Gadus callarius (L.), to form a conditioned response towards visual stimuli

IV. The capacity of the blennies, Blennius pholis (L.) and Blennius gattorugine Bloch, to form conditioned responses towards gustatory and olfactory stimuli

V. General remarks

VI. Summary

VII. References

\section{Introduction.}

THE present paper continues the account of my experiments on the capacity of fishes to form conditioned responses towards definite stimuli under strict experimental control. No change has been made in the method of recording the results except in the section on auditory discrimination in the wrasse. This slight variation is explained in the appropriate place.

All the experiments described in this part belong to Section A of the previous paper (1), in which food is the unconditioned stimulus. The work which has been carried out in Section B will receive fuller treatment at a later date. 


\section{The Capacity of the Wrasse, Crenilabrus melops (L.),} to Differentiate Between Two Different Sounds.

Being a continuation of the experiment described in Part I, p. 508.

Mention was made in the earlier paper (1) of the likely continuance of discrimination experiments with a wrasse which had already formed a stable conditioned response towards the stimulus of a tuning-fork vibrating at the rate of 128 d.v.'s per second. The discrimination attempted was a simple one, in which the fish had to establish an association between two new factors, in the form of an electric buzzer and a foodbottle at one end of the tank, as distinct from the original response involving entry to a food-bottle at the opposite end of the tank. In Figure 8, Part I, of these studies (1), page 508, B1 represents the position of the new food-bottle and its associated buzzer. All other parts are unchanged. The buzzer was of a common type used as a door-bell, enclosed in a stout brass box with a thin brass diaphragm, giving a somewhat harsh note of high pitch approximating to the note $\mathrm{F}$ in the 2 nd octave of the pianoforte scale, contrasting very strongly with the rich low note from the tuning-fork.

The results are given in Figure 1, a diagram requiring more detailed explanation for the sake of clearness. In any one section of this there is firstly a continuous base line along which dates are marked off as before. Above this are three horizontal sets of positions, the median one shown as a continuous dotted line. Where the original tuning-fork was used as the conditioning stimulus that test is denoted by the symbol $\mathrm{O}$, the symbol X signifying the uses of the buzzer as the signal. Each such symbol $\mathrm{O}$ or $\mathrm{X}$ entered at regular intervals along the record represents a single test, and the position of it in relation to the dotted line gives the behaviour of the fish.

Thus, referring to the first day's work recorded in the diagram, November 29 th, it is to be seen that 7 presentations of the auditory stimulus were given that day. The first two of these being the buzzer, $\mathrm{X}$, the next two, the primary stimulus of the tuning-fork, 0 . If the fish entered food-bottle B (the original response), no matter which stimulus preceded it, the diagram records a line starting from the median dotted line, then directed upwards to the symbol, and back again to the dotted line. Such, for example, was the response to the buzzer at the first of the tests recorded. If entry was to the opposite bottle B1 (the new response), there is shown a similar line directed downwards, and back again. At the fifth test of the first day this is the result recorded, the correct one for that stimulus - the buzzer. Should a vacillating response be the result, the fish going first to one bottle and then to the other, the order and course of this is shown as in the sixth test of the first day, 
by a dotted line in the corresponding directions, the symbol occurring at the top or the bottom depending on whether it was bottle $\mathrm{B}$, or B1, in which the fish finally came to rest. In the sixth test just mentioned, this was B1, the correct one. Not infrequently, there was no decisive entry to either bottle, and this is shown in the record by the appropriate symbol remaining on the dotted middle line, as, for example, in the last test of the day.

With this explanation the diagram becomes a concise picture of the
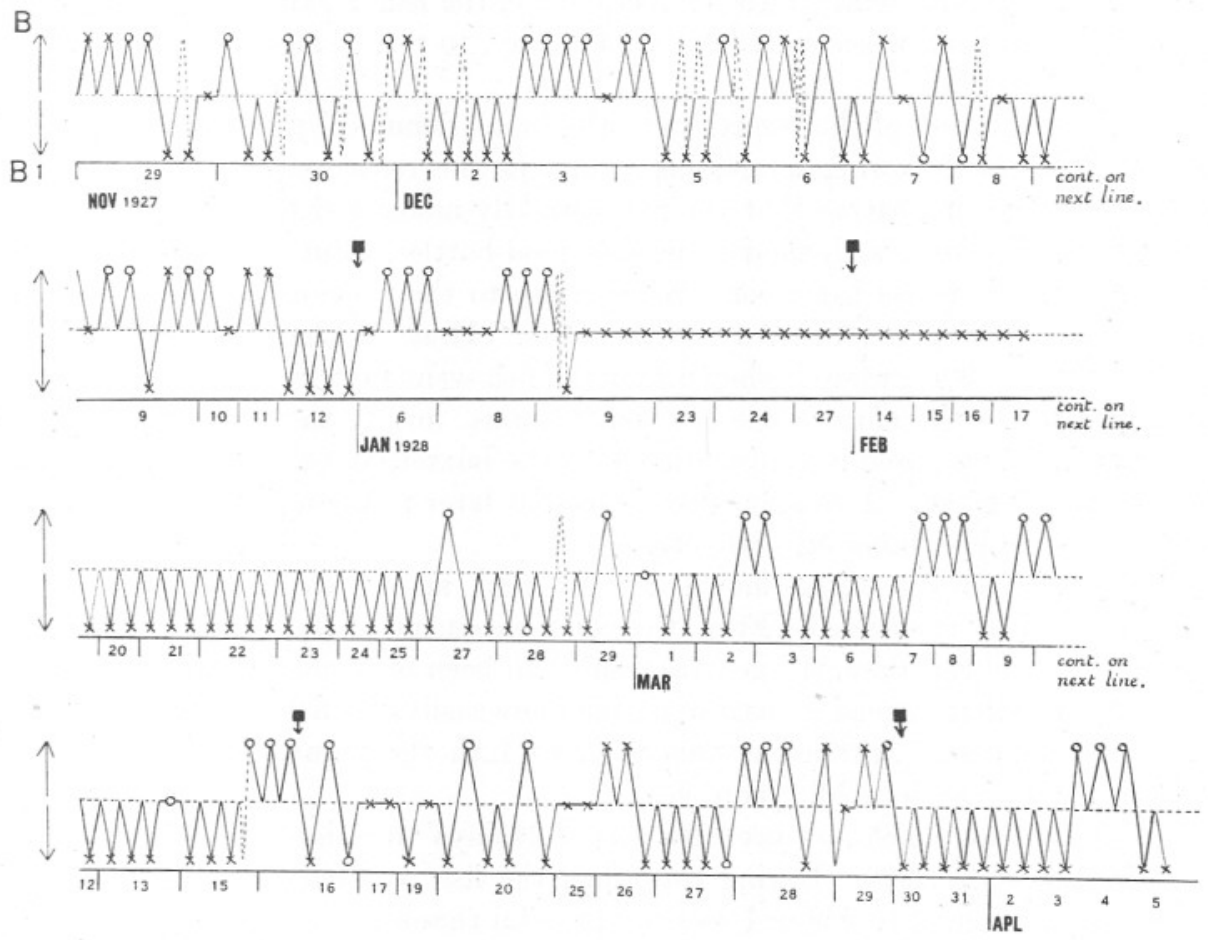

FIG. 1. Record of the discrimination between the sound of a tuning-fork and the sound of an electric buzzer shown by the wrasse, Crenilabrus melops, in the formation of conditioned responses.

Explanation in text : $\mathrm{O}=$ tuning-fork ; $\mathrm{X}=$ buzzer.

results obtained, but the more salient points may be outlined in a running commentary.

The introduction of the second bottle and the buzzer at once interfered with the very clear-cut result of the earlier experiments. Although on the first two occasions when the buzzer was used as the signalling stimulus the actual swimming response was a wrong one from the conditioned response point of view, yet the fish, in order to obtain the food used at those tests, finally entered the new bottle. Watched for 
some time between these and the next tests, the fish was seen to go first to the old bottle and then into the new one, showing an obvious and rapid learning of the relationship of the new bottle to food. It was a striking feature of the earlier conditioned response to the tuning-fork stimulus, that after entry into the food-bottle the fish continued to remain there making signs fairly to be described as anticipatory, until such time as food was given, if the giving of food was intentionally delayed, or not given at all; with the greater complexity this behaviour was somewhat modified. After entry into the food-bottle, the fish usually stayed but a short time, a few seconds, then swam away, to return after a greater or lesser interval.

Examination of the record up to the break denoted by the first arrow reveals the following interesting points in the response. Statistically, there is an indication that the fish correctly associated the buzzer, and the tuning-fork, with their respective food-bottles. But it is to be seen that the response bears some relationship to the previous, immediately preceding response in many of the tests. Thus, at the fourth test of November 30th, there is shown that the fish went first to bottle B1, and then to $\mathrm{B}$, the correct one for the stimulus, for, at the previous test, bottle $\mathrm{B} 1$ was used in conjunction with the buzzer, and the response was correctly given. A similar effect is seen at later tests on the same date, as also on December 5th, 6th, etc.

On December 12th, shown by the first arrow, experiments were temporarily suspended. From the commencement of the differentiation tests, until this date, the general result had been inconclusive, with some evidence that instead of discriminating more easily, the fish was becoming more confused. From December 7th to 12th the number of incorrect responses had decidedly increased.

The break which now occurred was of 24 days' duration, and lasted till January 5th, 1928. During this time, the fish was fed for me by Dr. Amirthalingam, to whom I owe my grateful thanks.

One very obvious fact emerges from a study of the responses given immediately after this date. It is to be seen that where the buzzer was used as stimulus, no definite response was noted, the fish not entering either bottle during two minutes' observation at these tests; whilst, on the other hand, when the tuning-fork was sounded, it at once elicited the original response of entry into bottle B. The explanation of this is probably to be found in the fact that this last is a much older, and therefore more stable response, for all my previous work shows that these responses, when once thoroughly established, are stable over long periods. The response involving entry to $\mathrm{Bl}$, associated with the buzzer, could not as yet be regarded as well established, and further, many incorrect responses had previously resulted when the buzzer was used. It was 
therefore decided, on January 27th (2nd arrow, Fig. 1), to continue with the buzzer alone, in the hope of establishing the response when not complicated by intermittent presentations of the sound of the tuningfork. But for a while the fish ignored all food, and it was not until February 14th that a serious start could again be made. At the next 9 trials, up to February 17th, there were still no signs that the process of forming this association was in any way advancing, so that it was somewhat surprising to get a clear-cut response to B1 at the third test of that date. This, however, initiated a fairly lengthy period from February 20th to March 15th, during which, at 45 separate trials, the fish never failed to enter bottle Bl when the buzzer was used as conditioning stimulus; 15 presentations of the tuning-fork were given at irregular intervals from February $27 \mathrm{th}$, the original and correct response resulting at twelve of these, and an incorrect one at only one test. On the remaining two occasions no response occurred, nor was food eaten when given. It appeared then that, by this date, the fish had truly learnt to discriminate between the sound of the buzzer, and that of the tuning-fork. There still remained the possibility, however, that it was the relative positions of the two sounds which was being discriminated, and not the sounds themselves. This was put to the test by placing the buzzer over by the bottle B at the opposite end of the tank, but otherwise continuing the tests unchanged (3rd arrow, March 16th, Fig. 1). During the next two weeks thirty tests were made. Of these, twelve tests gave a correct response to the buzzer, but ten were incorrect; two out of seven presentations of the tuning-fork were also followed by the wrong response. Here was a clear indication that it was the position of the two sounds which had been the factor discriminated. So on March 30th (4th arrow, Fig. 1) the buzzer was replaced in its original position. When tests were resumed there was no hesitation such as had persisted before this change back. The responses towards both the buzzer, and the tuning-fork, were given rapidly and correctly until April 5th, when the experiment was concluded owing to my taking up duties elsewhere.

There is ample evidence in these results for the conclusion that this specimen of a common wrasse, Crenilabrus melops, could rapidly form a stable conditioned motor response involving entry into a special bottle for food, using as the conditioning stimulus either a tuning-fork sounding the note lower $C$, or an electric buzzer giving a mixed note corresponding approximately to the note $F$ in the 2 nd octave, when these were used singly.

It could not, however, differentiate between these two sounds as sounds, if they were used to build up a differential response. The factor discriminated in such tests was found to be the place of origin of the sound, not the quality or nature of the sound. In this respect, the auditory sense of this fish appears to resemble the visual sense, when investigated in the same 
manner, for in reviewing the evidence on pp. 516 and 519 of the earlier paper (1) the conclusion was reached that in visual differentiation the source of light played a greater part in the discrimination than a wide range in the intensity of the two lights. Finally, it is interesting to note how strongly these conclusions upon two senses of major importance to man and most higher vertebrates contrast with the conclusions already reached upon the fineness of perception shown by the blennies in forming these responses towards thermal and salinity changes, and towards gustatory stimuli, such as are described in a later portion of the present paper.

III. (a). The Capacity of the Plaice, Plevronectes platessa (L.), to form a Conditioned Response towards Visual Stimuli.

The experiments described in this section, including the present one and the two following, were carried out in order to ascertain whether the

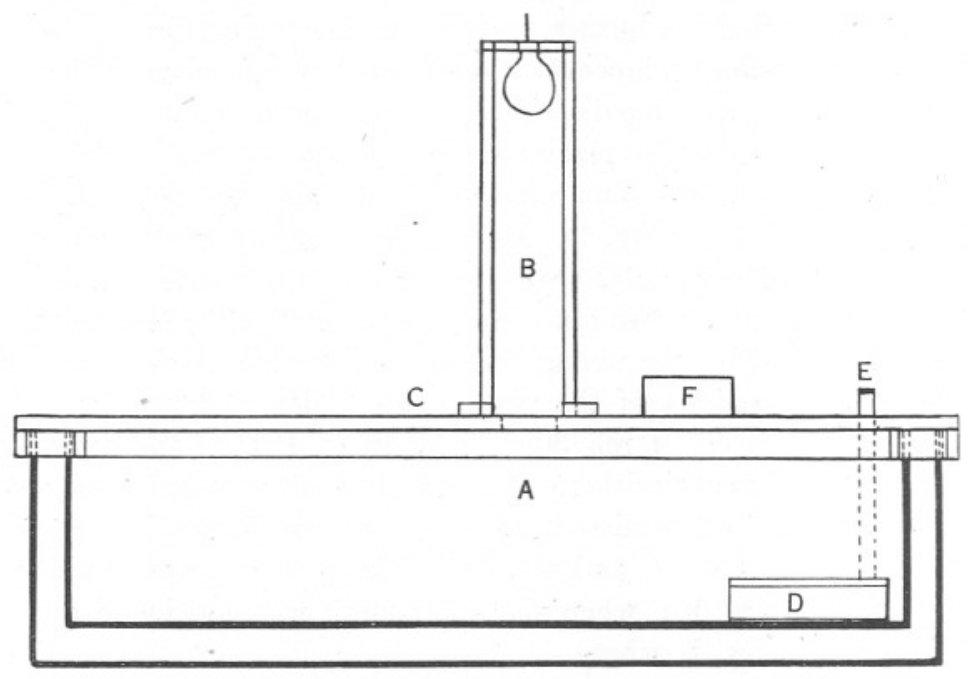

Fig. 2.-Diagram of apparatus used in the formation of a conditioned response in the plaice towards visual stimuli. Description in text.

results previously obtained with the wrasses $(1$, p. 510) were to be obtained generally amongst fishes of different habits.

Essentially, both the apparatus and the mode of experimentation were the same as there described, but minor changes were made to suit the conditions at the Cullercoats laboratory, where they were carried out. Figure 2 is a diagram of the tank and general arrangement. The tank was of concrete, $2 \mathrm{ft}$. by $3 \mathrm{ft}$. $6 \mathrm{in}$. by $10 \mathrm{in}$. deep. It was completely covered in, to exclude all light. A small hole, A (Fig. 2), 2 in. square, was 
cut out of the top, over which was placed the light chamber B, with a lantern slide-holder $\mathrm{C}$ at the lower end for use with Wratten light filters. The food-box D was rectangular, measuring $9 \mathrm{in}$. by $6 \mathrm{in}$. by $2 \mathrm{in}$. deep, with an opaque tube $\mathrm{E}$ leading down into it at the hindmost end, for the introduction of food. A periscope $\mathrm{F}$ fitted over the entrance to the foodbox served to note the response.

The visual stimulus was the unscreened light of a $100 \mathrm{w}$. opal gasfilled electric lamp, 12 in. from the water surface, suspended in the light chamber.

The mode of experimentation was at first the normal one for the type of experiment, i.e. light switched on, food in the form of a small piece of Mytilus introduced 30 seconds later; light then switched off after a further 30 seconds. But on December 8th, 1928, I was led to change this procedure in a marked manner. The reasons for this can be revealed in a

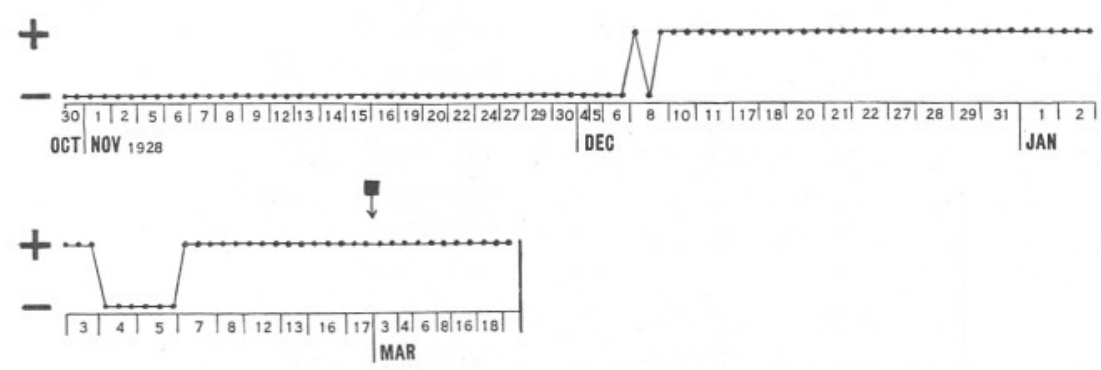

FIG. 3.-Record of the process of formation of a conditioned response in the plaice towards a visual stimulus. Explanation in text.

few words. It is to be seen from the diagrammatic record of the results in Figure 3 that the period of learning, or the period during which no positive conditioned response was noted, was a somewhat lengthy one (October 30th to December 8th). It appears from the record that the response came suddenly into operation on December 8th, and remained constant for a long period after. This early negative stage is therefore, I think, probably incorrectly recorded. I was puzzled at the unusual length of time which this fish was taking to build up the response, as compared with other fishes investigated. I had noticed also that, although a full 30 seconds was allowed after food was introduced, and before the light was switched off, the fish never became visible beneath the periscope during that time, yet on performing the next test, one hour or so later, the food had been taken. On December 8th, then, I removed the periscope, which only allowed of a limited field of vision, and settled down to watch the behaviour of the fish from the time the light appeared, taking especial care to remain quiet and still. As these tests were all 
carried out in late evening, the room was always in darkness, and it was not difficult to remain unobserved. By this means I was able to discover that the behaviour of the plaice was strikingly different from that of any of the other fishes with which I had worked.

For one minute the fish made no movement whatever. It then commenced to move slowly and hesitantly towards the illuminated area at the opening of the food-box, but with a curious side-to-side movementa short swim at an angle to the right of the direct path, then pause - then another short swim at an angle to the left-and in this erratic, slow, zigzag way the fish approached the opening of the food-box. Still with the same hesitant zigzag motion it entered completely into the food-box. After remaining motionless in the food-box for a further space of time, the fish suddenly took the food in the box, and then backed away quickly to a remote corner of the tank. The conditioned response was thus at this time already well formed, for the whole movement, though lasting twelve minutes, was directed in an obviously purposive manner. It should be added that, in the very early stages of conditioning, food was not introduced directly into the food-box only, but was divided into two portions, one of which was dropped into the tank at the opening of the food-box where it could be seen from any part of the tank, and the other placed in the food-box. It is clearly impossible to build up this response without doing this.

As a result of the observation just described, the light was left on in all subsequent tests for 15 minutes, or until such time as was required for the fish to complete the response, watching the whole time through the periscope. It soon became apparent that the suggestion that the response was already well-formed by December 8th was correct; for the behaviour of the fish at that test was typical of the conditioned response shown by this fish throughout the remainder of the tests. There was some variation in the time taken by the fish to enter the food-box completely, but it was rarely less than 2 minutes and more usually was 6 to 8 minutes. If no entry occurred within 15 minutes, as on January 4th and 5th, the response was regarded as negative. The fish ignored all food on these two days. With this exception the response was obtained at the whole of the tests made up to the date upon which the experiment was concluded, March 18th, 1929. This statement, however, ignores the fact that from January 18th to March 2nd the fish constantly refused all food, which was a feature shown by most of the aquarium fishes for the whole or portion of this time, owing to the intense cold then prevailing. An arrow indicates this date in the record. It was most interesting to find, when feeding was once more resumed on March 3rd, that the conditioned response had been in no way diminished in strength, or altered in nature by this long abstention. Such a high degree of retention, supported as it 
is by many similar instances from my other experiments, lends additional support to a suggestion made by me recently (3) that associations of this nature, when set up in natural conditions, may acquire sufficient stability to bring about a permanent change in the habits of a large body of fish, through the purposive association (by one or more of these fish) of some slight change in an environmental factor with more advantageous conditions of living.

III. (b). The Capacity of the Coad-Fish or Saithe, Gadus virens (L.), to form a Conditioned Response towards Visual Stimuli.

The apparatus and mode of experimentation was the same as that used in III $(a)$.

The results are given as a diagrammatic record in Figure 4.

The fish used was a small male, $14.5 \mathrm{~cm}$. long. The experiment was carried out alongside that on the plaice, using a similar $100 \mathrm{w}$. opal gasfilled electric lamp as the conditioning stimulus. Eighteen associations

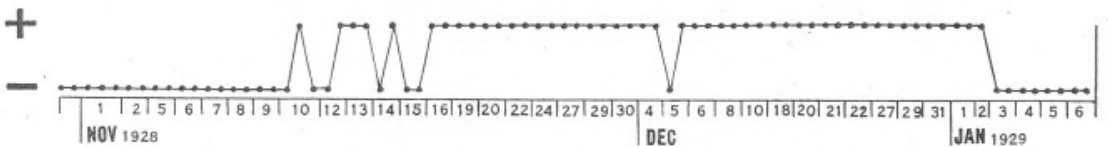

FIG. 4.-Record of the process of formation of a conditioned response in the coal-fish towards a visual stimulus. Explanation in text.

spread over the period October 31st to November 9th, 1928, were required before the first conditioned response was obtained. This was followed by a short period when the response was uncertain, lasting over a further period of nine trials of which four gave a positive response, and after November 16th the response was firmly established. On January 3rd the fish ceased feeding, and at tests carried out from the 3rd to the 6th January a completely negative result occurred. The fish was in a torpid condition. It may be recalled that the plaice also went off food on January 4th and 5th as well as from January 17th onwards. No further tests were made on the coal-fish after January 6th as it continued to refuse all food, and it eventually succumbed to the severe cold at the end of the month.

The diagrammatic record of the results needs no further comment.

The individual behaviour of this fish closely resembled that shown by the wrasses under these conditions. At an interval of from 10 to 25 seconds, no matter what was its position in the tank, the fish swam rapidly to the food-bottle, taking the food quickly when given, and swimming away again with equal rapidity. 
III. (c). The Capacity of the Cod, Gadus callarius (L.), to Form a Conditioned Response towards Visual Stimuli.

Essentially a repetition of the last experiment, the conditions of the test remaining unchanged.

The results are expressed in diagrammatic form in Figure 5 and require little comment, so closely do they follow those obtained in the last experiment. The commencement is shown as March 9th, 1929. Actually the experiment began on February 23rd, upon which date the fish was placed in the tank. Work was not at once possible, as the fish remained in a torpid state, eating no food, in common with the other specimens at this time. When more lively habits were shown, learning was fairly rapid, only nine days, covering 21 associations, being required before the first conditioned response was obtained. For a further period of 4 days, including twelve trials, the result was uncertain, but thereafter the

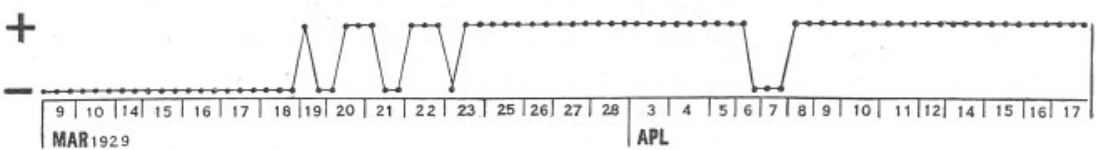

FIG. 5.-Record of the process of formation of a conditioned response in the cod towards a visual stimulus. Explanation in the text.

conditioned response was given invariably, except on April 6th and 7th, for which no reason was apparent. The experiment was concluded on April 17th. After my return from a cruise the fish was removed, and used for work on thermal stimuli to be described later.

IV. The Capactity of the Blennies, Blennius pholis (L.) and Blennius gattordgine Bloch, to form Conditioned Responses towards Gustatory and Olfactory Stimuli.

Blennies were again chosen to make the preliminary investigations into these two stimuli on account of the ease with which their responses can be noted and also for their general adaptability. They are additionally well suited to the object in view, since they are fishes which normally capture food by sight and not by taste or smell, so far as can be judged from ordinary observation. At the Plymouth Laboratory I used Blennius gattorugine throughout, but this species being rare at Cullercoats, it was necessary, on continuing the work there, to carry on with Blennius pholis. It is not, I think, likely that these two species should differ greatly in their response to this stimulus, but it is by no means improbable that there may be some slight variation, so the fact should be remembered in considering the results. 


\section{The Apparatus.}

After many slight modifications the apparatus shown in Figure 6 was the one finally used. It differs but little from the apparatus used in the earlier experiments on blennies. The whole of the right-hand side of the figure is exactly the same as that of Figure 5, p. 503, of the earlier paper (1), whilst the remaining parts in the left-hand side of the figure are simple changes to meet the requirements of the present stimulus. A is a straight 10-in. Liebig's condenser from which the inner tube was removed, graduated, and then replaced, afterwards connecting it with the tube $\mathrm{E}$

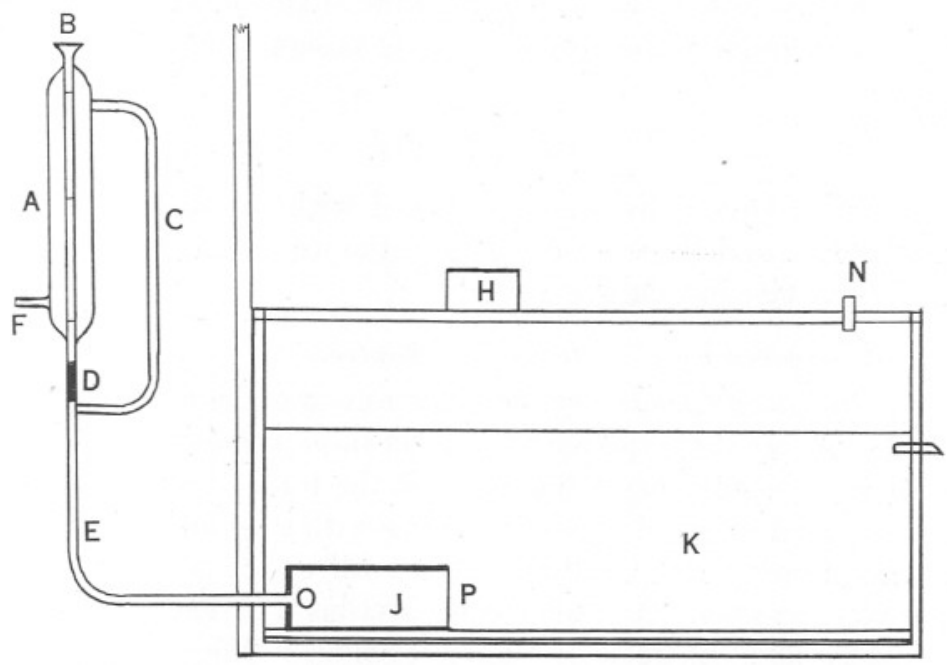

FIG. 6.-Diagram of apparatus used in the formation of conditioned responses in blennies towards gustatory and olfactory stimuli. Explanation in text.

which supplies the water to the aquarium via the home jar of the blenny. Water from the main aquarium supply enters the condenser at the lower end $\mathrm{F}$, passes upwards in the condenser and down again through the tube $\mathrm{C}$, to enter into the inner tube $\mathrm{E}$, immediately below the pinch-cock D. The solution to which the fish is to be conditioned is placed in the inner tube at the funnel B. By this system absolute equality of temperature is assured. The pinch-cock $\mathrm{D}$ is of a type familiar to many chemists but possibly not to biologists. It is especially easy to use, and accurate and noiseless in delivery, so that it is far preferable to the ordinary patterns for this purpose. A description is given by Sutton (2). The rate of flow of the main current of water into the tank was maintained constant at 20 c.c. per second. 


\section{Method of Experimentation.}

The routine of the tests was again that of the salinity and temperature experiments. The taste solution is placed in the inner condenser tube and left for ten minutes for temperature equalisation. When ready, pinchcock D is opened and the experimental solution flows into the main stream ; 10 c.c. was used and the time taken to enter the ingoing stream was 5 seconds. Food is dropped into the tank 15 seconds later through the opening in the screen N. The fish, if healthy, and desirous of food, at once swims to the spot, takes the food, and returns to its jar. The object in view, as in previous experiments of a similar nature, is to ascertain whether the fish can build up the response involved in the capture of food, to the stimulus of the solution serving as signal for that food.

\section{The Results.}

These are of two kinds-those obtained with the use of "natural" sapid solutions, and those resulting from the use of an " unnatural " or artificial substance in solution.

\section{A. Results obtained with " natural" substances.}

At the Plymouth Laboratory, nereid worms was the food most readily available. In all the experiments on Blennius gattorugine which were made there, the gustatory stimulus took the form of extracts of these worms, obtained by grinding up the worms with sand and sea-water, and afterwards filtering the resulting extract till clear, using the vacuum pump and glass-wool. At Cullercoats, Mytilus and Patella formed the main food supply. Extracts of these were made in the same way.

Specimen No. 1. Blennius gattorugine, $\hat{\jmath}, 12 \mathrm{~cm}$.

After being installed in the apparatus on August 14th, 1927, it was thought first of all, that it would be interesting to attempt to build up the conditioned response towards a solution which had merely stood in contact with the living worms in an intact and healthy condition. From August 15th to 31st such a solution was given three times daily unaccompanied by food but without any resultant response. The solution was made by taking several worms, and after washing them thoroughly in sea-water placing them in 100 c.c. of sea-water for 24 hours. It was soon felt, however, that there was little chance of stabilising the strength or nature of this solution, and the experiment was then dropped. On September 1st a fresh start was made with the definitive worm extract made in the manner described above, and in the first place, of a strength of $0.5 \%$, i.e. $0.5 \mathrm{grm}$. of Nereis diversicolor (live, wet weight) to 100 c.c. sea-water. 
A diagrammatic record of the results is given in Figure 7.

After no more than nine associations of this solution, the conditioned response became apparent at the first test made on September 3rd. Two further tests on the same day gave no observable response, but the fourth again produced it, and from then onwards it became firmly fixed. The generalisation of stimuli observed with others was again found to occur here, for two days later, on September 5th, when a $0 \cdot 1 \%$ solution, indicated in the diagram of the results by a well-defined square dot, was tried, three successive tests elicited the conditioned response. Three succeeding tests with the original $0.5 \%$ extract diluted ten times, i.e. a $0.05 \%$ solution (shown in Fig. 7 by black triangle) were followed at the first by no observable response, but at the two following ones by wellmarked positive responses.

It should here be added, that in order to eliminate any possibility that

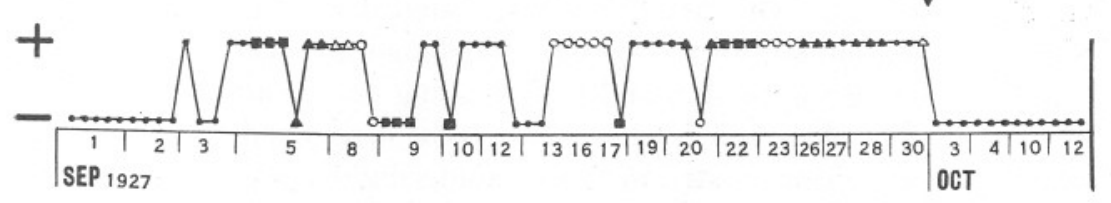

FIG. 7.-Record of the process of formation of a conditioned response in Blennius gattorugine towards gustatory stimuli. Specimen 1 . Explanation in text.

$\bullet=0.5 \%$ extract of Nereis diversicolor (primary stimulus).

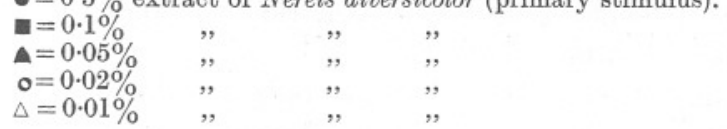

some movement or change in conditions other than that of the worm extract might be responsible for bringing about the response, frequent controls were carried out. On September 8th, 12th, 20th, 22nd, and 29th, all possible movements of taps and tubes were made several times over, but using the aquarium sea-water only in place of the worm solution. Not one of these was followed by an observable response, and it can be safely asserted that this solution was indeed acting as sole stimulus. After the control tests had been made on September 8th, the fish was presented with a solution only one-fiftieth the strength of the original or primary stimulus, i.e. a $0.01 \%$ solution (shown in Fig. 7 by an open triangle), and the conditioned motor response again occurred at two such tests. A little later in the same day a $0.02 \%$ solution (shown in Fig. 7 by a plain circle o) brought about the response, but several hours later this failed to do so. The following morning, September 9th, tests one to three, this negative result continued with the $0.01 \%$ solution, but later in the afternoon, when presented with an extract of the original strength, $0.5 \%$, the fish gave the characteristic response. 
A study of the diagrammatic record up to the date indicated by the arrow shows plainly that the response was being given with greater certainty, as the number of associations was increasing, negative responses being given only on isolated occasions. It is noteworthy also that the conditioned responses could be brought about with any of the solutions tried, i.e. solutions containing from 0.01 to $0.5 \%$ of worm. This experiment thus provided the first indications obtained by me, that this type of stimulus may be as generalised in its perception by the fish, as the thermal or salinity changes previously recorded. 'I had hoped to begin a complete investigation into the extent of this, but on September 30th (arrow) I found that the fish had inexplicably got out of the tank and was picked up from the floor almost dead. It did, in fact, recover sufficiently to give the appearance of normal health and tests were carried out with the primary stimulus, $0.5 \%$ solution, up till October 12 th, though quite without any signs of obtaining the conditioned response; neither would the fish take food. On the 12th it was found dead. The figure shows plainly the inhibitory effect of such a disturbing influence.

In considering the results, and their bearing on the actual perception of the stimulus, there is a further factor to be considered. Whilst being introduced into the main stream of water entering the tank, the gustatory solution is subjected to dilution. Measurements of time of flow, and the quantity of water passing in that time, show that this dilution is approximately ten times. On account of diffusion this would be still greater when it reached the receptors of the fish.

With this fish then, it was shown that, not only was it able to perceive, but it could also form a conditioned response towards, a solution containing $0.5 \mathrm{grm}$. of worm in 100 c.c. of sea-water, and that it could react similarly towards one containing $0.01 \mathrm{grm}$., and to various intermediate concentrations.

Specimen No. 2. Blennius gattorugine, o, length $13 \mathrm{~cm}$.

After being used for experiments described in the next section, this specimen was taken to repeat the observations made on Specimen 1. Work was begun at once, as the fish had already been in the apparatus the whole of the previous month. The stimulus was the same as the primary one in the last example.

The results are presented in Figure 8. The general impression received is that the results are not of the clear-cut and decisive nature which it is so desirable to obtain, in order to arrive at any positive conclusions upon the sense of discrimination. So erratic was the behaviour of this fish that this stage was never reached, yet the results are none the less interesting from other points of view when examined. In the early stages, after the second day, the actual behaviour of the fish showed 
clearly that the stimulus was being perceived. When the sapid solution was entering, the fish frequently made irregular body movements, accompanied by the peculiar gulping and chewing movements of the mouth, such as were noticed in the advanced stages of the experiments on blennies with thermal and other stimuli. In the description of these, I referred to these movements as additional features of the conditioned response, occurring only when this was firmly established, and to be regarded as anticipatory in nature. These movements are such as might be actually expected if the stimulus was affecting the taste buds of the mouth region. But there is also some individuality about it, for it was not seen at any time in specimen 1 , and in all the experiments where it has appeared, it has only done so after one or more associations of stimulus with food. Beyond this, there is nothing in the diagrammatic record which needs further comment.

It is a fitting place, however, to make a few general remarks upon the

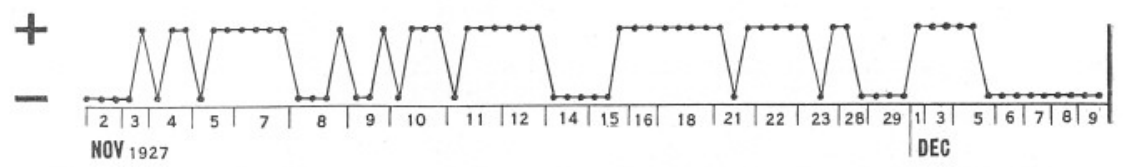

FIG. 8.-Record of the process of formation of a conditioned response in Blennius gattorugine towards gustatory stimuli. Specimen 2. Explanation in text.

use of this method in investigating any total behaviour response. If such a record as that showing the results of the present experiment were the result of an ordinary subjective type of experiment with a similar object, it could not be regarded as satisfactory positive evidence of gustatory perception. Such a result in those circumstances would need to be analysed statistically, and in considering the whole period of the experiment, it would be found that there are 40 occasions where the conditioned response was evoked, 33 where it was not. It would be concluded that the evidence is indeed slightly in favour of a positive perception, but nothing more could be said. On the other hand, under the conditions of the present tests, and by very reason of the nature of the response studied, it is not permissible to use a mathematical analysis of the record to determine whether chance has, or has not, played any part in the result after the response has once been built up. The real reason for the irregularity of the conditioned response in this fish must be sought in some internal factors of the fish, which are unknown to us. It was, for instance, from the moment when it was brought to the Laboratory, of a sluggish nature. On December 9th the experiment was stopped whilst I was absent from the Laboratory until January 5th, 1928. During this time the fish was plentifully supplied with food, but none 
was eaten ; more significant still, the abdomen was found distended with eggs when I returned. It was therefore impossible to continue the experiment further as previous experience had shown what has since been abundantly confirmed, that the onset of gonad development in female fishes entirely inhibits the building up of conditioned responses. I have no evidence that it does so in male fishes.

Specimen No. 3. Blennius gattorugine, §ิ, $11 \mathrm{~cm}$.

The taste experiments in this example were again preceded by other experiments described in the next section which lasted from January 26th to February 27th, 1928.

The results are presented in Figure 9, showing a typical picture of conditioned response formations in fishes. From February 28th to March 27th (arrow) the fish was given 38 associations of a solution
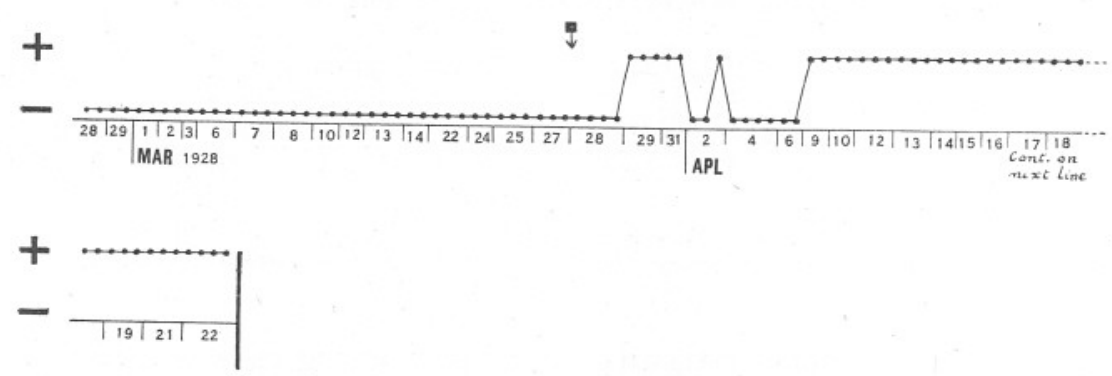

Fig. 9.-Record of the process of formation of a conditioned response in Blennius gattorugine towards gustatory stimuli. Specimen 3. Explanation in text.

containing 1 grm. of worm in 1000 c.c. of sea-water, i.e. a $0 \cdot 1 \%$ solution, but no signs of the conditioned response appeared. It was therefore decided on March 27th to increase the strength of the extract to $0 \cdot 4 \%$. With this new solution four further associations only were required to bring about the conditioned response, accompanied also by vigorous mouth movements which had not appeared with the lower concentration. After a short period of no responses, from April 2nd to 6th, the responses became definite and never failed to appear at the remaining associations made until the experiment was concluded by my leaving Plymouth for Cawsand.

Specimen No. 4. Blennius pholis, 우, $11 \mathrm{~cm}$.

Results in Figure 10.

After being used for experiments in the next section, it was found impossible to continue at once with the experiments with sapid substances, owing to the development of the ovaries, and the refusal of food. These eggs were shed in March, 1929. The fish was again feeding freely by 
April 2nd and a start was made on April 3rd (shown by arrow). The portion of the record preceding this represents the results with artificial musk as stimulus, which are here included in the same figure, in order to contrast a consistently negative result with the typical result obtained when perception is positive.

The conditioning stimulus was here changed from the worm solution such as was used in specimens 1-3 to a solution containing $5 \mathrm{grm}$. of Mytilus edulis in 1000 c.c. of sea-water, extracted by grinding with sand and filtering through glass-wool using the vacuum pump. Continuing the
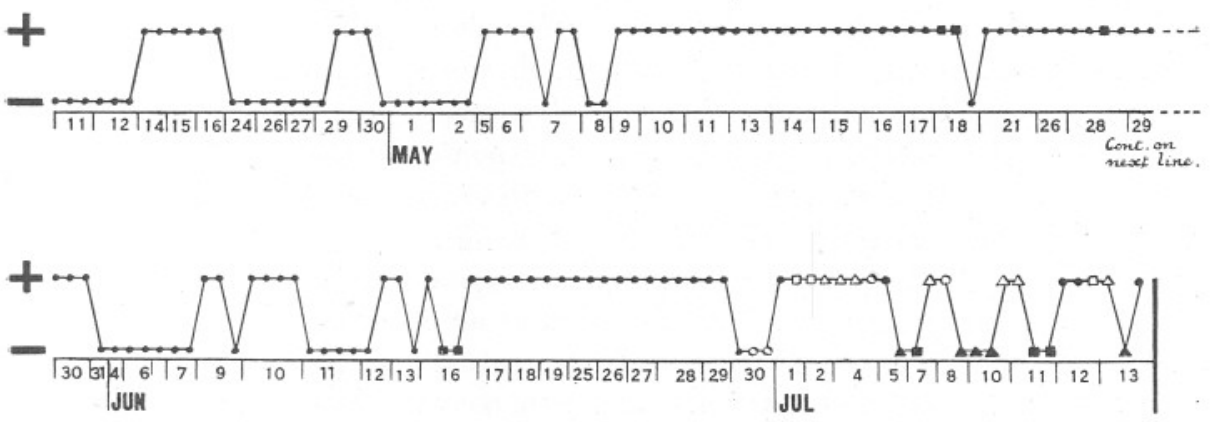

FIG. 10.-Record of the process of formation of a conditioned response in Blennius pholis towards gustatory stimuli, including also a record of experiments on the same fish with artificial musk. Specimen 4. Explanation in text.

Symbols.

Before April 3rd $\bullet=$ artificial musk.

After April 3rd $\bullet=0.5 \%$ extract of Mytilus.

$\begin{array}{lll}\mathbf{0}=0.02 \% & , & , \\ \square=0.01 \% & , & , \\ \Delta=0.0075 \% & , & , \\ \mathbf{\Delta}=0.00375 \% & , & , \\ \mathbf{m}=0.0015 \% & , & ,\end{array}$

routine as before, with the 15 -second interval between stimulus and food, seventeen associations of this stimulus were required before the first conditioned response was obtained. It was a response however, differing in several important particulars from that shown by any of the specimens of Blennius gattorugine investigated at Plymouth. Instead of the direct swimming response to the food place, which was always shown without other motor complications in that species, the response here obtained was made up of a vigorous body movement directed away from the opening $\mathrm{P}$ (see Fig. 6, P) and towards the incoming taste solution at 0 . It should be added for those who are not familiar with the habits of these fishes, that 
the fish when at rest is usually in a slightly curved position with the tail at 0 and the head just inside the opening of the home jar; the curve of the body adapted to fit as close as possible to the hindmost corner (see Fig. 6). When returning to the jar after taking food, the fish enters head-first, but at once turns round and fits itself to this position. So that this complete turn round at the beginning of the conditioned response is a striking movement, especially when accompanied, as it frequently was, by deliberate biting at the incoming solution! It was also obtained in a parallel experiment on the same species shortly to be described (Specimen 5). There are, I believe, two possible explanations for this new development. (1) That it represents an actual specific difference in the behaviour of the two species; (2) that the solution of the Mytilus has a different physiological significance to the fish.

It seems hardly likely that the second of these two can be the reason, for it would have been expected that such a movement would result from the stimulus straightway, and without the association with food. It is more probable that it is a true specific physiological difference between the two species, and indicating that Blennius pholis has not lost the capacity for unconditioned gustatory response so completely as has Blennius gattorugine. I have considered the neurological significance of this reformed gustatory response elsewhere (3). It remained a definite feature of the fulfy formed conditioned response towards the primary stimulus, and is therefore to be regarded as an essential part of it. For this reason, even when not followed by actual movement to the food place, I have recorded in the diagrammatic record as a positive response, all those occasions where this biting and turning response occurred. Practically the whole of the positive results up to May 17th were of this nature. There was a rather lengthy period, from April 12th to May 8th, during which the response gradually became more firmly established. From May 21st onwards the fully formed conditioned response was given invariably in response to the primary stimulus, whilst the biting and turning-back movements continued to precede it.

The effect of external conditions is noticeable at June 4th, 6th, 7th, 9 th, and 11th, upon which days there were many disturbances in the room prior to the carrying out of the tests, including loud hammering. On June 29th the tank was cleaned, resulting in inhibition on the following day, June 30th. For all the negative results shown in the record subsequent to May 8th there was a well-defined cause. On June 30th tests were begun to ascertain the extent of generalisation of this stimulus, and the limits of perception. Different symbols are employed in the diagram to denote tests with extracts of different strengths, the details of which are given in the legend.

It is to be seen that by making use of the principle of generalisation of 
stimuli, the positive conditioned motor response continued to be given to extracts containing $0.5 \%$ (the original and primary stimulus), $0.02 \%$ (a plain circle in the record), $0.01 \%$ (a plain square), and $0.0075 \%$ (a plain triangle), of Mytilus, whilst a consistently negative result was obtained when either of the two following and much lower concentrations was tried,--.00375\% (a black triangle), and $\cdot 0015 \%$ (a black square).

Specimen No. 5. Blennius photis, $\widehat{0}, 10 \mathrm{~cm}$.

Results in Figure 11.

This experiment was started on June 12th, 1929, the fish having been brought in from the shore that very morning and placed directly in the experimental tank. On the 12th, 13th, and 14th I introduced three times each day 10 c.c. of a solution containing $0.5 \mathrm{grm}$. of Patella vulgata in 100 c.c. of sea-water extracted in the the same way as the Mytilus extract

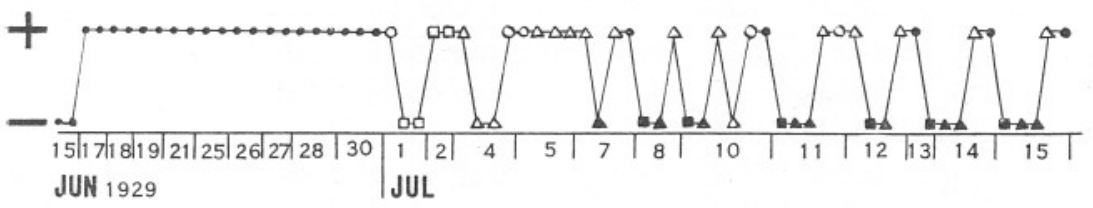

FIG. 11.-Record of the process of formation of a conditioned response in Blennius pholis towards gustatory stimuli. Specimen 5. Explanation in text.

Symbols.

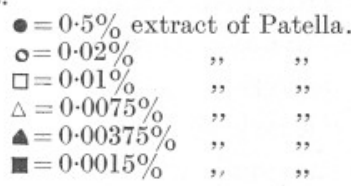

used for Specimen 4. This solution formed the primary conditioned stimulus for this experiment. There was no response whatever shown when the above tests were applied.

On the morning of June 15th, 1929, a start was made with the process of conditioning, and the first association made of the Patella solution with food (a small piece of Patella) given 30 seconds later. This interval is a longer one than any yet tried. A second association was made later in the day. On neither of these two occasions was there any sign of the conditioned motor response ; the food when given was fetched, and eaten at once in a typical healthy manner. At the third association of the series, given on the morning of June 17th, I was very surprised to get a perfect response to the Patella solution. Immediately after the solution had begun to enter the jar containing the fish, its head appeared at the opening and exhibited violent gulping movements-an exact replica of those described in Specimen 4 when the response had been perfected. At 10 seconds the fish turned round facing the incoming 
solution and biting at it. At 25 seconds it resumed the normal position, and then went straight across the tank to the food-hole where it stayed until food was given at 60 seconds (intentionally delayed). The fish took this at once with great avidity, and returned quickly to the jar. This constituted a record for my experiments in the number of associations required to bring about this type of response, and it was still further remarkable in that it continued to be given throughout the remainder of the experiments without the least hesitation or failure.

It was soon apparent that this specimen was an ideal one for ascertaining the range of perception for such a stimulus by means of the process of generalisation. This was begun on July 1st and the diagrammatic record clearly indicates the strengths of the solutions employed and the resultant responses. The symbols used in the figure represent the same strengths of solution as in the last specimen. It was most interesting to find that the conditioned response failed to occur with the same strengths of Patella extract as the Mytilus extract which was inadequate in Specimen 4, whilst the lowest strength which was able to bring about the response was also the same $(0 \cdot 0075 \%)$.

Certain features which were common to the behaviour of both Specimens 4 and 5 appear to have some significance in deciding the nature of the perception of this type of stimulus. These concern the appearance of the biting and gulping movements and the sharp turn backwards to bite the incoming extract. I have elsewhere (3) concluded that this phase of the total response represents a reformation of the typical gustatory response as defined by Herrick (4), and which characterises all fishes which at the present time normally seek their food by the aid of gustatory organs. It appears then that this may be built up under experimental conditions, although under their ordinary conditions of living, both of the species of blennies we have investigated have lost this originally dominant sense. In both species also this reformed gustatory response was not obtained at any time when the strength of the extract of Mytilus or Patella used as stimulus was lower than $0.02 \%$, although the characteristic motor response remained unchanged. This would seem to indicate that olfaction has been associated with gustatory perception in building up the response, and that in the response to the lower concentrations it (olfactory perception) has taken over the whole or major part of the perception. At the present stage this suggestion is only hypothetical.

Summarising these experiments, it may be said that these fishes, the blennies, are able to form conditioned motor responses towards gustatory stimuli, that the stimulus is capable of wide generalisation, and that the limits for perception of extracts of Mytilus or Patella lie between the strengths represented by the 0.0075 and $0.00375 \%$ solutions, 
equivalent to an actual stimulation by concentrations slightly less than one-tenth of this.

\section{B. Results obtained with artificial substances.}

Although I have spent much time at work on this section only one definite result is available, and that of a negative kind. Ultimately a comparison between this section and the last should prove of great interest in defining the exact meaning of gustation and olfaction in fishes.

The object has been to ascertain whether under the same conditions as those of the last section blennies are able to build up the conditioned response to artificial substances, whose concentration in sea-water is such that it can be firmly regarded as a stimulus of a true olfactory nature. A stimulus of this nature is hard to find, for it is very difficult getting such a solution without changing some major factors in the chemical equilibrium of the water. Artificial musk, Trinitro-butyl-toluene, a perfume of cheap soaps, was regarded as fulfilling all requirements. It is not actually soluble to any measurable extent in sea-water, but by adding $1 \mathrm{mgrm}$. to 1000 c.c. of sea-water, shaking vigorously, and allowing to stand for 24 hours, a solution possessing a highly characteristic and penetrating perfume could be obtained.

By carrying out the experiments in the typical manner, associating the giving of 10 c.c. of this solution with the giving of food 15 seconds later, the result was a totally negative one in all the fishes investigated. Of the fishes used in the last section, and previously used here,

Specimen 2 received 51 such associations over a period of three weeks ;

Specimen 3 received 70 spread over a period of four weeks; and

Specimen 4, as shown in the first part of Figure 10, was given 64 between November 1st and 24th, 1928.

These experiments taken together provide good evidence that Blennius gattorugine and Blennius pholis are both unable to perceive this substance in solution when it is presented to them in this manner.

\section{GENERAL REMARKS.}

A fairly large body of evidence has now been collected by the experiments on visual stimuli. This is sufficient, I think, to enable one to regard the capacity to build up these associations between food and some visual stimulus as general amongst fishes. The experiments on the cod and the coal-fish indicate that the association proceeds just as readily in fishes which under natural conditions do not normally rely so much upon vision as upon other modes of perception, as it does in fishes which do, such as the wrasse and blenny. 
It was considered more important to investigate this before proceeding to a finer analysis of vision in one or two species. These experiments are well in hand, and I hope shortly to be able to make a comprehensive statement of visual acuity and colour sense of at least one species of Blennius, and later to contrast it with such a form as Motella, where the role of vision is a very insignificant one in normal life.

In the deseription of the experiments throughout, many seemingly small details have been mentioned, as I believe them to have value in a final analysis of fish behaviour, and especially when we shall come to a closer comparison of these results with those obtained by a large number of investigators in the dog. This comparison was one of the principal objects of the investigation. In carrying out the work, however, it has become evident that information of more immediate economic application is made possible by the use of this method, so that this aspect is now being given first consideration.

Owing to the length of time taken by these experiments, however, and the great interest of the results for comparative psychology as well as fishery research, it is much to be desired that other workers should take up special aspects of the problem, or work out the finer details in regard to one particular receptor system, such as $\mathrm{H}$. Stetter (5) has recently done with the auditory system.

There are many environmental stimuli which are potential governors of fish movement and behaviour, but of whose influence we know absolutely nothing. This is especially so with those factors which have not a direct influence upon the fish, and which cannot in themselves have either a beneficial or a noxious influence. It is for this very reason that it is impossible to ascertain their effect by ordinary methods. Whether the present type of experiment will help, still remains to be seen. The experiments in Section 4 of the present paper lead me to hope that it will. Occasionally difficulties of a perplexing nature arise. In the course of an investigation on the capacity of a cod to form a conditioned response towards an induced temperature gradient in a 10 -ft. tank, I had to abandon the test after more than two months' work owing to the fish having taken up a more or less permanent position in the food-box!

\section{SUMMARY.}

1. The wrasse, Crenilabrus melops, is able to form stable conditioned motor responses to the note of a tuning-fork, sounding the note lower C, or to an electric buzzer giving a mixed note corresponding to the note $\mathrm{F}$ in the second octave, when either of these is used singly. In a discrimination test employing both these sounds the wrasse was not able 
to distinguish between them as sounds, but differentiated them by their position.

2. Conditioned responses involving visual stimuli have been built up in the following additional species : plaice, cod, and coal-fish. Individual variations in the response are described.

3. Blennius gattorugine and Blennius pholis are able to form stable conditioned responses towards gustatory stimuli such as sea-water extracts of natural food substances. These stimuli are widely generalised in their action. The limits for perception lie between concentrations slightly less than $0.000375 \%$ and $0.00075 \%$ of the weight of living food substance in sea-water. Many significant details in the responses are described and discussed.

These fishes do not appear to be able to respond to an artificial olfactory stimulus such as artificial musk.

4. The essential similarity between these responses and conditioned reflexes in dogs is becoming more emphasised as the data accumulate.

\section{REFERENCES.}

1. Buld, H. O. Studies on Conditioned Responses in Fishes. Part I. Jour. Mar. Biol. Assoc., N.S., Vol. XV, No. 2. 1928.

2. Sutton, F. A. A Systematic Handbook of Volumetric Analysis. 11th Edition, p. 11, Fig. 9. J. \& A. Churchill. 1924.

3. Buld, H. O. On the Nature of Purposive Movement in Fishes. Rep. Dove Mar. Lab. 1929, p. 39.

4. Herrick, C. J. The Organ and Sense of Taste in Fishes. Bull. U.S. Fish Comm., Vol, XXII, 1902 (1904), pp. 237-272.

5. Stetter, H. Untersuchungen über den Gehörsinn der Fische, besonders von Phoxinus lævis L. und Amiurus nebulosus Raf. Zeit. f. vergl. Physiol., 9 band, 2/3, Heft, pp. 349-477. 1929. 
